\title{
分析工程测量中 GIS 技术和数字化测绘技术的应用
}

\section{The Application of GIS Technology and Digital Mapping Technology in Engineering Survey \\ 周志伟 侯增强 张骁}

Zhiwei Zhou Zengqiang Hou Xiao Zhang

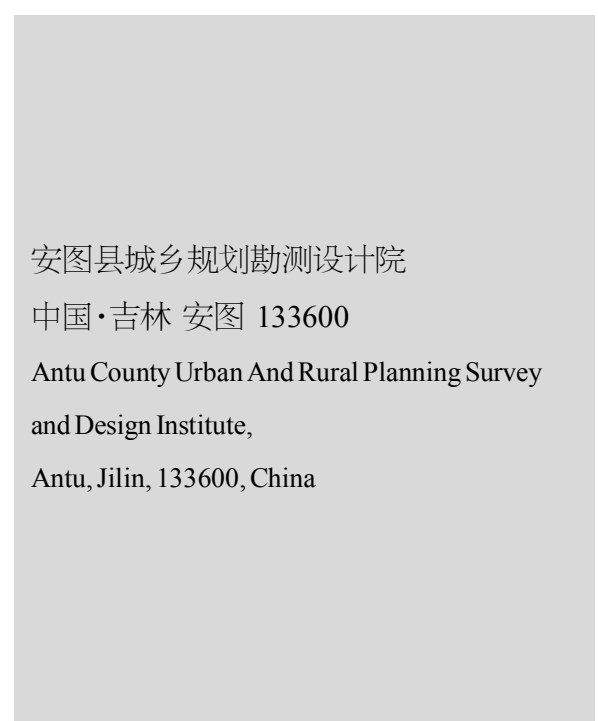

\section{1 引言}

现如今，随着数字化技术与 GIS 技术的被提出和广泛应 用, 有效地提高了中国工程测量工作的整体测量质量, 保证了 测量结果的准确性, 从而为中国工程建设奠定了良好的基础, 并进一步推动了中国工程建设行业的发展。

\section{2 工程测量技术的发展现状分析}

在中国如今的工程测量工作中,主要测量的内容就是测 量方法和测量技术的选择以及数据信息的处理, 在工程建设 中, 必须要通过工程测量方法收集与确定工程项目的结构式 设计、勘察施工现场、分析施工方法等, 只有做好工程测量工 作, 才能够确保工程项目建设可以顺利开展与完成, 并进一步 提高中国工程项目建设的整体质量。随着科学技术水平的不 断提升, 信息技术也不断发展,在这一过程中 GIS 技术与数字 化测绘技术也被广泛应用于工程测量工作中，从而提高了工 程测量工作的效率与质量, 为中国工程项目的建设奠定了坚 实的基础。

\section{GIS 技术在工程测量中的应用}

GIS 技术已经具备了非常明显的科学化与信息化标志, 其主要就是利用地理分析系统处理与分析数据, 并对数据进 行整改与整合, 而后再与专业人员进行整理与分析 ${ }^{[1,}$, 以此进
一步推动与引导数字化系统的发展和规划。与此同时, 再对技 术水平不断地进行测试, 并通过规范化的操作与专业的指导, 确保 GIS 技术能够在工程建设中得到更加广泛的应用, 这样 一来就能够为工程建设项目提供更加准确的数据信息, 从而 更好地推动与操作 GIS 技术在工程测量中应用的效果。

GIS 技术的实际应用过程中，主要就是利用计算机系统 完成操作,在这一过程中,将地理信息作为关键内容,而后整 合各个学科的知识, 并将其进行结合, 其中具体包括环境科 学、地理学、空间科学、遥感科学、信息学管理以及地图学等, 将其结合后形成 GIS 技术。因为 GIS 技术能够在工程项目建 设中可以获取到更多的地理信息, 同时也能够分析、查询、储 存以及管理相关的信息。GIS 技术应用时,将工程项目中的实 际测量数据信息作为基础, 从而实现对数据的科学化管理,而 且也可以利用数据信息完成图形的制作，并提供实时查询功 能与信息数据处理功能, 以此来为工作人员提供辅助功能。所 以说,GIS 技术主要就是将处理后的信息数据作为技术应用 的出发点,做好决策工作, 充分地发挥出 GIS 技术具有的分析 与指导功能 ${ }^{[2]}$ 。

\section{4 数字化测绘技术在工程测量中的应用}

\section{1 数字化测绘技术的特点}

数字化测绘技术在实际应用有所突破和改变，也具有明 
显的现代化与科技化特点。结合如今的发展需要进行分析, 采 用数字化测绘技术能够更好地满足工程建设项目的建设需 要 ${ }^{[3]}$ 。首先, 通过数字化测绘技术可以实现数据的自动化处 理,在该技术的实际应用过程中,可以利用计算机技术对所提 供的数据进行处理, 完成绘图测绘, 而且通过数字化测绘技术 下所绘制的图像, 其准确性也特别高。其次, 通过数字化测绘 技术也能够对绘制好的图像进行编辑, 因为数字化测绘技术 在完成绘图后, 通常会因为一些外界因素的影响, 而使绘图发 生一些变动, 而在数字化测绘技术的作用下, 能够确保不破坏 整体的情况下,改进或者编辑图形。最后,在数字化测绘技术 中也合理地采用了 TRK 技术, 在工程项目建设过程中, 数字 化测绘技术通过合理的运用 TRK 技术, 则能够进一步提高工 程测量结果的准确性，从而为工程项目建设的后续建设提供 更加准确的数据信息。

\section{2 数字化测绘技术的实际应用}

在目前的工程项目建设中, 数字化测绘技术已经得到了 非常广泛的应用,并且已经获取了非常巨大的成果与成就, 尤 其是在科学技术水平不断提升的今天，采用数字化测绘技术 所采用的成果与成就也得到了越来越多人的认可。同时,随着
激光技术、计算机技术等技术的被提出和发展, 也进一步拓展 了数字化测绘技术的应用范围, 并提高了数字化测绘技术在 工程建设项目中的应用效果, 从而提高数据测绘结果的可靠 性和准确性, 推动与加快中国工程项目的建设步伐和发展。

\section{5 结语}

综上所述, 在工程项目的建设过程中, 工程测量工作是非 常重要的,其会直接对工程建设项目的质量造成影响, 同时也 能够确保工程建设的安全性和稳定性, 以此来提高工程建设 的效率, 而利用数字化测绘技术与 GIS 技术开展工程测量, 则 能够使测绘步骤更加简洁，使工程测量工作能够更加高效的 开展。

\section{参考文献}

[1]王淑一. 数字化测绘技术及其在工程测量中的应用 $[\mathrm{J}]$. 居业， 2019(10):5-6.

[2]李勇.浅谈数字化测绘技术和地质工程测量的发展应用[J].国 土资源,2019(10):44-45.

[3] 孙瑞泮.新形势下工程测绘作业测量技术的研究分析[J].中国 标准化,2019(8):135-136.

\section{（上接第 30 页）}

行地形测量,在城市比例尺的基础上进行更新和优化,在很大 程度上提升了工程测量的整体水平。

\section{4 无人机测绘技术}

无人机测绘技术是一项新兴的测绘技术, 其具有灵活性、 高效性等优势,在工程测量中得到了有效应用,具体体现在以 下方面: 首先, 根据地理测绘的精准性需求,合理地调整无人 机的航拍比例尺,完成航摄野外,在航拍完成后需要针对最初 获取的数据进行审核, 且像控点和相片需要专业人员进行连 接。其次,测绘技术人员可以利用相关软件准确地针对航空摄 影内部进行处理,这样影像图像会被输出, 并对影像图中的各 项地测信息进行判断和检查。最后, 在数字化绘图过程中, 测 绘技术人员需要根据前期获取的影像图和数据进行, 提高工 程测量结果的精度。

\section{5 遥感技术}

现阶段, 遥感技术在工程测量中得到了有效应用, 是工程 测量中的重要内容之一。其中, 航空摄影技术是遥感技术应用 的基础, 在工程测量过程中, 测量技术人员需要充分发挥出遥 感技术在工程测量中的应用优势，以此确定测量工作的范围 和比例,搜集小比例尺、中比例尺的地形图数据,认真分析基
本的地形图测量数据, 为工程测量工作的顺利实施提供支持, 在规定时间内完成交付使用 ${ }^{[3]}$ 。因此, 在工程测量过程中, 遥 感技术的应用为工程建设工作的有效开展提供了支持, 有利 于提升工程建设的整体质量。

\section{4 结语}

综上所述, 在现代化测绘工程测量中, 测量新技术发挥着 重要作用,为工程测量工作提供了新的发展方向, 在很大程度 上提高了建筑施工企业的综合效益。在建筑工程项目建设过 程中, 测量技术人员需要引进测绘新技术, 充分发挥出其在工 程测量中的作用, 获取更多准确的测量结果, 提高工程测绘的 整体效率, 为施工企业节省更多的成本, 确保工程项目如期交 付使用。因此,在现代化工程测量中, 测绘新技术发挥着重要 作用,有利于提升工程项目建设的整体质量。

\section{参考文献}

[1]何天鹏,刘琦.测绘新技术在建筑工程测量中的应用分析 [J].工 程技术研究,2019,4(23):35-36.

[2]萧雁宾.测绘新技术在测绘工程测量中应用的探讨实践思考 [J].智能城市,2019,5(14):93-94.

[3] 李云,王宏建,张文宁.测绘新技术在工程测量中的应用探究 [J].工程建设与设计, 2019(9):22-23. 